\title{
RBEP
}

\section{Políticas afirmativas para a inclusão do surdo no ensino superior: algumas reflexões sobre o acesso, a permanência e a cultura universitária}

Marilda Moraes Garcia Bruno

\section{Resumo}

Discute as políticas e as ações afirmativas para a inclusão de pessoas surdas no ensino superior no Estado de Mato Grosso do Sul. Problematiza, no contexto da educação inclusiva, as condições de acesso e de permanência do acadêmico surdo nos níveis mais elevados de ensino. Fundamenta-se na análise de documentos normativos, em pesquisas realizadas no período de 2006 a 2010 e nas reflexões socioanalíticas sobre o registro de experiências para a implementação das propostas do Projeto Incluir na Universidade Federal da Grande Dourados (UFGD). Os resultados revelam melhorias nas condições de acesso e de permanência dos acadêmicos surdos no ensino superior e a transformação da cultura universitária mediante as ações afirmativas adotadas em todas as unidades de ensino da instituição.

Palavras-chave: educação superior; surdez; inclusão e cultura universitária. 


\section{Abstract \\ Affirmative policies for the inclusion of the deaf in the higher education: some reflections about accessibility, permanence and university culture}

The article discusses the affirmative policies to the inclusion of the deaf in the higher education in Mato Grosso do Sul state. It analyzes the higher education access and permanence conditions concerning the inclusion of the deaf. The study was based in documental analysis and researches that were carried out from 2006 to 2010 as well as in some socio-analytical reflections about the experiences for the implementation of the proposals of Incluir in the higher education in the Federal University of Dourados. The results not only showed a gain in the deaf students' access and permanence conditions but also to a change in the university culture as a result of the affirmative actions adopted by the institution.

Keywords: higher education; deafness; inclusion and university culture.

\section{Introdução}

A democratização da educação superior no Brasil, para as políticas públicas e para a cultura universitária, apresenta dois grandes desafios: o primeiro, a garantia do acesso; o segundo, a promoção da aprendizagem para a permanência de pessoas surdas nas universidades públicas e privadas em nosso País.

As pesquisas sobre o acesso das pessoas surdas ao ensino superior são escassas, e alguns dados estão inseridos em dados gerais nos estudos acerca do ingresso de pessoas com deficiência no ensino superior. Nesse sentido, Valdés (2006) diz que, até o início da década de 1980, poucas pessoas tinham acesso à educação superior no Brasil, fato esse associado ao não acesso dessa população à educação básica, o que indicava sua exclusão dos direitos sociais.

Quanto ao ingresso de jovens e adultos com deficiência no ensino superior, pesquisa de Torres (2002) informa que as dificuldades de acesso ao conhecimento nos níveis de ensino anteriores comprometem a formação acadêmica desses alunos. A pesquisa constatou que grande parte das dificuldades enfrentadas pelos alunos com deficiência é detectada no processo seletivo para o acesso à universidade, no vestibular, exame que exige determinadas competências e conhecimentos.

As estatísticas oficiais e as pesquisas indicam que as preocupações são mais com os desempenhos na educação básica do que com o ensino 
superior. A pesquisa de Moreira (2005) revela que são poucos os dados sobre a situação dos alunos com necessidades educacionais especiais no ensino universitário, o que indica a carência de reflexões e de políticas públicas direcionadas para esse nível de ensino.

A experiência educacional de surdos no ensino médio e superior foi acompanhada de frustrações e de insucesso, devido à ausência de satisfação das necessidades específicas desses educandos nesses níveis de ensino, bem como pela ausência de uma proposta bilíngue na educação. Nesse sentido, Sander (2002) diz que a presença de intérpretes de Língua Brasileira de Sinais (Libras) para acadêmicos surdos, no ensino superior, é uma experiência recente na universidade brasileira.

Diante dessas constatações, cabe então questionar: como tem sido o acesso das pessoas surdas ao ensino superior? Quais as ações e as estratégias que têm facilitado/dificultado o acesso e a permanência das pessoas surdas no ensino superior?

Para tanto, este trabalho discute as políticas e as ações afirmativas para a inclusão de pessoas surdas no ensino superior no Estado de Mato Grosso do Sul. Procura problematizar, no contexto da educação inclusiva, as condições de acesso e de permanência do acadêmico surdo nos níveis mais elevados de ensino. Para tanto, os procedimentos utilizados para a coleta de dados foram: busca e apreciação de documentos nos sites das Instituições de Ensino Superior (IES); visitas às universidades para estudo de documentos e projetos pedagógicos; análise das grades curriculares, programas e projetos especiais.

Para refletir sobre essas questões, num primeiro momento, o trabalho questiona se as políticas afirmativas têm garantido o acesso e a permanência da pessoa surda a esse nível de ensino. Depois, são apresentados dados de pesquisa com reflexões socioanalíticas sobre a cultura universitária; e, por fim, compartilha algumas experiências de ações afirmativas propostas no Projeto Incluir, no ensino superior, como a implementação do Polo Letras Libras e do Laboratório de Acessibilidade e Inclusão no ensino superior, criado na Universidade Federal da Grande Dourados (UFGD), em Mato Grosso do Sul (MS).

\section{As políticas afirmativas têm garantido o acesso e a permanência do surdo na educação superior?}

As políticas afirmativas para a democratização do ensino superior e a inclusão de pessoas surdas, nesse nível de ensino, ganham força, no Brasil, a partir da Constituição Federal de 1988, a qual busca efetivar uma política pública de acesso universal à educação. O texto da Lei estabelece a "igualdade de condições de acesso e de permanência na escola" (Brasil, 1988, Art. 206).

As diretrizes político-normativas brasileiras acerca da inclusão de pessoas com surdez no ensino superior ganham força com os movimentos internacionais, como a Conferência Mundial de Educação para Todos, 
realizada em Jomtien, Tailândia (1990) e em Salamanca, Espanha (1994), e a Conferência Mundial sobre Educação Superior, realizada em Paris (1998), as quais orientam a inclusão de pessoas com necessidades educacionais especiais em todos os níveis de ensino.

As reivindicações do movimento dos surdos no Brasil são contempladas pela Lei de Diretrizes e Bases da Educação Nacional (LDB) de 1996, a qual preconiza o acesso ao ensino superior mediante a adoção da linguagem Libras e da língua portuguesa na modalidade escrita. É importante salientar que esse documento tornou-se um marco do reconhecimento das necessidades específicas de comunicação e de sinalização inerentes à condição das pessoas surdas no processo educacional.

Especificamente, em relação ao acesso e à permanência de pessoas com deficiência no ensino superior, o Ministério de Educação (MEC), por meio do Aviso Circular n 277/96, orienta as IES sobre a viabilização do processo de acesso de educandos com necessidades educacionais; orienta o processo seletivo de ingresso com a adequação do concurso vestibular; e recomenda a flexibilização dos serviços educacionais, a infraestrutura e a capacitação de recursos humanos, de modo a proporcionar a permanência com qualidade no ensino superior (Brasil. Ministério da Educação, 1996).

Para regulamentar as normas anteriores, a Portaria MEC n 1.679/99 determina que sejam incluídos requisitos de acessibilidade de pessoas com necessidades educacionais especiais nos instrumentos destinados a avaliar as condições de oferta de cursos superiores para fins de autorização, reconhecimento, credenciamento ou renovação, conforme as normas em vigor. No entanto, passados 15 anos, o quesito acessibilidade ao processo seletivo e a oferta de oportunidades educacionais aos surdos no ensino superior ainda não se tornou realidade em muitas universidades brasileiras.

Quanto à oferta de vagas nesse nível de ensino, o Plano Nacional de Educação (PNE), Lei no 10.172/2001, reconheceu a existência de um déficit na oferta de vagas e matrículas de alunos com deficiência, principalmente no ensino superior. Recomendou diretrizes curriculares que assegurassem flexibilidade e diversidade nos programas de estudos oferecidos pelas diferentes instituições de educação superior; a formação docente do professor; a acessibilidade física e o atendimento educacional especializado.

A qualidade da oferta educacional, com o acesso ao conhecimento no ensino superior, fica assegurada pela Lei no 10.436/02, a qual reconhece a Linguagem Brasileira de Sinais (Libras) como meio legal de comunicação e expressão e determina que as instituições públicas e privadas apoiem o uso e a difusão dessa língua. Orienta ainda a inclusão da Libras como parte integrante do currículo nos cursos de formação de professores e de fonoaudiologia.

Nesse sentido, a Portaria $\mathrm{n}^{\circ} 3.284 / 03$ dispõe sobre a responsabilidade das IES, públicas ou privadas, em assegurarem condições de acesso, permanência e atendimento especializado aos alunos com deficiência sensorial e física na educação superior.

As principais iniciativas governamentais para a concretização da política de inclusão educacional, no ensino superior, surgem com o Decreto 
no 5.296/04, que estabeleceu normas e critérios para a promoção da acessibilidade às pessoas com deficiência ou mobilidade reduzida. Esse Decreto impulsionou o MEC/Sesu a elaborar o Programa Incluir no ensino superior, como forma de garantir a acessibilidade universal aos espaços públicos, à instrução e ao conhecimento nesse nível de ensino.

No Brasil, a formulação de uma política linguística é muito recente; surge com o Decreto 5.626/2005, o qual reconhece a cultura surda e a educação bilíngue como formas de acesso e de permanência nos diferentes níveis de ensino. Assim, a Libras passa a ser a primeira língua de instrução da pessoa surda, e a língua portuguesa concebida como segunda língua na modalidade escrita. Prevê ainda a presença do tradutor/intérprete de Libras e língua portuguesa em todos os níveis de ensino.

A formação de professores na perspectiva da educação inclusiva foi assegurada pela Resolução do Conselho Nacional de Educação (CNE/ CP 1/2002), que estabeleceu Diretrizes Curriculares para a Formação de Professores para a Educação Básica. As instituições de ensino superior devem prever, em sua organização curricular, formação docente voltada para a atenção à diversidade e que contemple conhecimentos sobre as especificidades dos alunos com as necessidades educacionais especiais.

A Política Nacional de Educação Especial na Perspectiva da Educação Inclusiva, do MEC/Secretaria Nacional de Educação Especial, disciplina, pela primeira vez, a educação especial no âmbito do ensino superior: "Na educação superior, a educação especial se efetiva por meio de ações que promovam o acesso, a permanência e a participação dos alunos" (Brasil, 2008, p. 16). Essas ações envolvem o planejamento e a organização de recursos e de serviços para a promoção da acessibilidade arquitetônica, nas comunicações, nos sistemas de informação e nos materiais pedagógicos, os quais devem ser disponibilizados nos processos seletivos e no desenvolvimento de todas as atividades que envolvam o ensino e a extensão. Torna-se importante pontuar que as universidades brasileiras devem assegurar aos acadêmicos com deficiência o atendimento educacional especializado nesse nível de ensino.

Apesar dos esforços do MEC/Sesu/Seesp no sentido de desenvolver políticas de Estado para combater a situação de exclusão vivenciada pelas pessoas com deficiência, no momento do ingresso ao ensino superior, a fragilidade das práticas pedagógicas não permite ainda, de forma satisfatória, no momento do ingresso, o acesso à comunicação, à informação e ao conhecimento para a permanência nesse nível de ensino.

\section{A cultura universitária}

O Censo da Educação Superior, do Instituto Nacional de Estudos e Pesquisas Educacionais Anísio Teixeira (MEC/Inep/2006) informa que houve evolução significativa do acesso de pessoas surdas nas instituições públicas de ensino nesse ano, em relação aos dados de 2005. O censo de 2005 indicava a presença de 1.318 estudantes matriculados 
em instituições públicas e 4.074 estudantes matriculados em instituições privadas. O censo de 2006 indica que houve o quantitativo de 1.855 matrículas no ensino público e 5.105 no ensino particular (Brasil, MEC/ Inep, 2005, 2006).

Esses índices são animadores; entretanto, cabe ponderar que a elevação do número de matrículas não se deve à transformação da cultura universitária, mas às ações afirmativas de projetos especiais do MEC, da Universidade Aberta do Brasil (UAB) e da Universidade Federal de Santa Catarina (UFSC), entre 2006-2008, para a implementação dos cursos de licenciatura específica de Letras/Libras e Bacharelado/Intérprete, em 18 universidades públicas brasileiras, o que aumentou, significativamente, o acesso de pessoas surdas ao ensino superior.

Cabe questionar: o que esses dados representam? O vestibular tem se constituído a porta de entrada, gargalo ou situação de promoção da exclusão/inclusão de pessoas surdas? Como são formados ou preparados os professores do ensino superior na perspectiva da educação inclusiva? Como a comunidade universitária reage frente à diferença cultural, social, intelectual, sensorial ou de qualquer natureza? E o currículo é flexível, aberto à diversidade e à diferença? E a prática pedagógica contempla as necessidades específicas e educacionais nesse âmbito de ensino?

Essas questões nos remetem não apenas ao campo dos direitos sociais ou do "direito à diferença" como direito fundamental; passa, a meu ver, por uma questão cultural, pela maneira de pensar o outro, o diverso e o diferente.

Nesse contexto, cabe refletir sobre como os planos de desenvolvimento institucional e os projetos político-pedagógicos dos cursos universitários têm pensado, repensado ou reagido diante da diferença e da deficiência. Como o currículo e a prática pedagógica têm lidado com níveis diferenciados de produção da língua portuguesa? E a prática pedagógica, contempla as necessidades específicas e educacionais nesse âmbito de ensino? E os alunos de culturas distintas, linguagens e códigos diferenciados, têm os seus exames vestibulares e suas avaliações pedagógicas, no decorrer do curso, adequados às suas diferenças e às suas necessidades educacionais?

Recorro aqui à dialética inacabada de alguns autores que nos ajudam a repensar a cultura da diversidade, da diferença, e o lugar do outro diverso e do deficiente na cultura universitária.

Autores como Foucault, Derrida e Deleuze nos ajudam a pensar a diferença pelo contrário, pela "desconstrução" do paradigma ocidental da homogeneidade. Derrida (1972) fala de uma ressurgência indefinida do irredutível no homogêneo, de um pensamento do diverso, pensamento-outro, na sua infinita reciprocidade, na sua intensidade nômade, que busca as conexões e os acontecimentos.

O pensar a diferença como acontecimento é proposto por Foucault (1980, p. 59) como desconstrução, o contrário de um paradigma que se anuncia e foge de toda fragmentação ou da certeza da finitude. "O pensamento diferente, o pensamento da diferença - um puro acontecimento; e quanto à repetição, já não seria um triste emaranhado do idêntico, mas diferença descoberta". 
A cultura ocidental e, por conseguinte, a cultura universitária, tem sido construída historicamente, fundada nos pares ou categorias dicotômicas, tais como: belo-feio, perfeição-imperfeição, normalidade-anormalidade, eficiência-deficiência do pensamento positivista - conceitos esses constituintes do paradigma da homogeneidade, tão presente, ainda, no ambiente universitário.

Pensar diferentemente a diferença, como sugere Foucault, passa por libertar o pensamento por meio da dúvida, da interrogação e da suposição. Pensar a pessoa deficiente no contexto universitário nos leva, então, a indagar: Por que a presença de pessoas diferentes, com maneiras diferentes de ser, perceber, pensar, aprender e fazer, nos mobiliza? Por que a presença de alunos com deficiência, em qualquer nível de ensino, inquieta e angustia o professor? Por que a representação da deficiência é conotada como ausência, falta e incompletude? Por que nos sentimos, muitas vezes, incapazes de lidar com o diverso, com o diferente e com o deficiente?

O filósofo Deleuze no seu livro Diferença e repetição pode nos trazer alguma pista (2006, p. 372), quando discute identidade e diferença como ilusão: porque os conflitos, as oposições, as contradições nos parecem efeitos de superfície, epifenômenos da consciência, ao passo que o inconsciente vive de problemas e de diferença. A história, diz o filósofo, não passa pela negação e pela negação da negação, mas pela decisão dos problemas e pela afirmação das diferenças. Nem por isso é ela menos sangrenta ou cruel. Só as sombras da história vivem da negação, mas os justos entram nela com toda a potência de um diferencial posto, de uma diferença afirmada; eles remetem a sombra à sombra e somente negam em consequência de uma positividade e de uma afirmação primeiras.

O autor recorre ao pensamento de Nietzsche para explicar que, entre os justos, a afirmação é primeira. Ele afirma a diferença, sendo o negativo apenas uma consequência, um reflexo em que a afirmação se reduplica. A contradição não é a arma do proletariado, mas a maneira pela qual a burguesia se defende e se conserva à sombra atrás da qual ela mantém sua pretensão de decidir os problemas. O negativo é a reação da consciência, a desnaturação do verdadeiro agente, do verdadeiro ator. As contradições não são resolvidas, são dissipadas (Deleuze, 2006, p. 372-373).

Para Deleuze, a diferença só implica o negativo e se deixa levar até a contradição, na medida em que se continua a subordiná-la ao idêntico. Ele defende o conceito de diferença sem negação, pois a diferença, não sendo subordinada ao idêntico, não iria até a oposição e a contradição. Ele alerta, ainda, para o perigo de se invocar diferenças puras, totalmente libertadas do idêntico, e que o maior perigo consiste em cair nas representações da "bela-alma", das diferenças conciliáveis do tipo "somos diferentes", mas não opostos. A noção de problema está ligada à noção de diferença e parece nutrir o estado de bela-alma quando só contam os problemas e as questões do ser, mas de modo algum, o ser do negativo. O problemático e o diferencial determinam lutas ou destruições em relação às quais as do negativo não passam de aparência e os votos de bela-alma, 
de mistificações a partir da aparência. O filósofo diz que não é próprio do simulacro ser uma cópia, mas subverter todas as cópias, subvertendo também os modelos.

Observa-se que lidar com o diverso, com as deficiências e as diferenças linguísticas não são conflitos simples, mas situações complexas que passam por representações socioculturais, por valores éticos e questões políticas e econômicas.

A metáfora do teatro político, escolhida por Buras e Apple (2008), ilustra as lutas travadas pelo acesso e pela permanência das pessoas surdas no ensino superior. São lutas dialéticas entre ações hegemônicas e contra-hegemônicas; são lutas educacionais, intimamente vinculadas a conflitos nas áreas econômica, política e cultural mais amplas.

No campo da cultura universitária, o discurso da inclusão, como nos alertam Derrida e Deleuze, pode, ilusoriamente, aparentar um discurso de políticas afirmativas voltadas para a afirmação das diferenças. Nesse processo, corre-se o risco de o discurso da inclusão ser engolido pelo discurso hegemônico do assistencialismo ou da discriminação, pela não crença na capacidade do outro. Recorre-se, assim, ao discurso da negação e ao esvaziamento do discurso da diferença, quando os exames vestibulares e demais avaliações, no decorrer dos cursos, não se efetivam em Libras.

\section{Avanços e desafios para o acesso e a permanência no ensino superior}

O acesso e a permanência de pessoas surdas no ensino superior tiveram grande evolução com o Projeto Letras Libras, parceria entre o MEC/Secretaria Nacional de Educação à Distância/Secretaria Nacional de Educação Especial e a Universidade Federal de Santa Catarina (UFSC), que, em 2006, ofereceu quinhentas vagas (500) nos nove polos, com 55 vagas em cada instituição de ensino. Em 2008, os cursos de licenciatura e bacharelado ofereceram novecentas vagas (900) distribuídas nos 15 polos, com 60 vagas cada, sendo 30 para a licenciatura e 30 para o bacharelado. Hoje, as instituições públicas que oferecem o curso de Letras Libras são: UFSC, Universidade Federal da Bahia (UFBA), Universidade Federal do Ceará (UFC), Universidade Federal da Grande Dourados (UFGD), Universidade Federal de Santa Maria (UFSM), Universidade Federal do Espírito Santo (Ufes), Universidade Federal do Pernambuco (UFPE), Universidade Federal do Paraná (UFPR), Universidade de Brasília (UnB), Instituto Nacional de Educação de Surdos (Ines), Universidade de São Paulo (USP), Universidade Federal do Amazonas (Ufam), Universidade Federal do Rio Grande do Sul (UFRGS), Universidade do Estado do Pará (Uepa), Universidade Estadual de Campinas (Unicamp), Centro Federal de Educação Tecnológica de Goiás (Cefet/GO), Centro Federal de Educação Tecnológica de Minas Gerais (Cefet/MG), Centro Federal de Educação Tecnológica do Rio Grande do Norte (Cefet/RN).

A UFSC, coordenadora-geral do projeto, tem respondido a esses desafios de diversas formas, principalmente com a criação de uma 
estrutura nos centros responsáveis pela formação, e tem primado pelo desenvolvimento de um modelo pedagógico e operacional adequado à realidade e às necessidades brasileiras na área de formação de professores e intérpretes. Os cursos de Licenciatura e Bacharelado em Letras/Libras oferecem a possibilidade de formar profissionais - o instrutor de Libras e o intérprete de Libras/Língua Portuguesa - , possibilitando a inclusão das pessoas surdas nos diferentes níveis educacionais, no mercado de trabalho e na sociedade.

Esses programas especiais voltados à implementação de políticas linguísticas, equiparação de oportunidades, sensibilização da comunidade universitária quanto às atitudes e as práticas afirmativas; à adequação da estrutura física e curricular; ao estímulo a programas inovadores de ensino-pesquisa-extensão estão restritos aos cursos de Letras e Pedagogia, o que não garante o acesso e a permanência de pessoas surdas a outras carreiras universitárias.

\section{$\mathrm{O}$ que dizem as pesquisas?}

Pesquisa de Castanho (2007) sobre a política para a inclusão de alunos com necessidades educacionais especiais, na universidade e centros universitários de Santa Maria, RS, revela que há esforços mais direcionados ao acesso, no concurso vestibular, e que não há ações mais concretas que favoreçam a permanência dos alunos no ensino superior.

Estudos de Forster e Fagundes (2006) sobre inovações educativas na sala de aula universitária indicam a necessidade de ruptura com a forma tradicional de ensinar e de aprender, com os procedimentos acadêmicos inspirados nos princípios positivistas da ciência moderna; de mediação entre as subjetividades dos envolvidos e o conhecimento, incluindo a dimensão das relações e do gosto, do respeito mútuo, dos laços que se estabelecem entre os sujeitos que se propõem a conhecer; o protagonismo, compreendido como a participação dos alunos nas decisões pedagógicas.

Nesse sentido, Strobel (2008, p. 27) afirma que o "modo de os sujeitos surdos agirem e verem o mundo constitui-se uma cultura estrangeira para os ouvintes". Nos estudos sobre os surdos (Skliar, 1997; Perlin, 2000; Strobel, 2008; Quadros; Sumpf; Gesser, 2009), a surdez não tem sido localizada nos discursos sobre a deficiência, na falta de linguagem e no espaço da educação especial. Esses autores situam a surdez no campo da diferença linguística e cultural.

O reconhecimento da surdez no campo da diferença linguística e cultural, em universidades públicas e privadas no Estado de Mato Grosso do Sul, tem sido negado, fato evidenciado na pesquisa Análise das políticas públicas de inclusão no ensino superior, realizada por Bruno e Coelho (2010), que constataram por meio da análise dos Planos de Desenvolvimento Institucional (PDI) e dos editais dos concursos vestibulares, que, embora as universidades se intitulem instituições abertas e voltadas para o desenvolvimento humano e social, observa-se que, em 
seus editais para a inscrição no processo seletivo, nada consta em relação ao atendimento às necessidades educacionais especiais e às adequações das provas ou do curso para o acesso de alunos surdos.

\section{Ações afirmativas na UFGD}

Em termos de política institucional voltada à inclusão social e educacional, a UFGD tem avançado significativamente nos últimos anos. Em 2007, contava com cerca de 2.700 alunos em 16 cursos. No Programa de Reestruturação e Expansão do Ensino Superior, criou nove novos cursos e conta, hoje, com 5.200 acadêmicos matriculados. Entre os cursos criados, cabe destacar a Licenciatura Indígena, com 120 alunos em duas turmas; os cursos de Licenciatura Letras Libras, para acadêmicos surdos; e o Bacharelado Intérprete de Libras. Ao todo, a UFGD conta com 21 acadêmicos surdos, três com deficiência física, dois com deficiência visual e um com deficiência intelectual.

Além dessas ações afirmativas, a instituição implementou em todos os cursos o sistema de cotas, com no mínimo $25 \%$ de vagas para egressos de escolas públicas, intensificando a oferta de bolsas direcionadas para esses estudantes se manterem na universidade.

Buscou-se uma renovação pedagógica mediante proposta que atendessem aos princípios da diversidade, heterogeneidade e interculturalidade, com a adoção da língua portuguesa como segunda língua para a população indígena e os surdos. Essas medidas são válidas tanto nos exames vestibulares quanto no decorrer dos cursos.

Assim, a renovação pedagógica na educação superior compreende: a flexibilização e a articulação curriculares e a organização curricular por ciclo de formação, geral e específico. O ciclo de formação geral consiste em oferta ampla de disciplinas voltadas para uma formação sólida nas áreas das ciências humanas, sociais, política e cultural, essenciais para a formação profissional e ética do cidadão. O ciclo de formação profissional começa na segunda etapa da graduação e aprofunda-se na pós-graduação.

Desse modo, essas metas e estratégias propostas nas outras dimensões do plano de inclusão estão tendo impacto direto e significativo na redução da taxa de evasão. Além dessas estratégias integradas, outras ações afirmativas foram implementadas:

- Projetos de ensino que atuam como ações de nivelamento, com o objetivo de compensar lacunas na formação escolar dos alunos ingressantes, principalmente nas áreas de língua portuguesa, matemática e informática;

- Ampliação dos meios de subvenção estudantil, como a assistência à permanência e à alimentação;

- Criação de bolsas pró-estágio, monitoria, programa de educação tutorial, possibilitando aos alunos maior acesso à remuneração vinculada, sem que isso comprometa o tempo dedicado ao estudo; 
- Ampliação de bolsas de extensão e pesquisa voltadas às ações afirmativas;

- Projeto de atendimento psicossocial para alunos com dificuldades;

- Criação do Laboratório de Acessibilidade de Práticas Inclusivas (Lapei), que realiza avaliação e acompanhamento dos acadêmicos com necessidades específicas e educacionais especiais; elabora a adequação dos exames vestibulares; e orienta a eliminação de barreiras atitudinais, físicas e instrucionais no interior da universidade;

- Reformulação dos projetos pedagógicos, com ênfase na flexibilização curricular, no uso de estratégias para a promoção da aprendizagem e da inclusão educacional (novas regras de avaliação, monitorias e estágios de docência);

- Ampliação dos eventos de extensão e cultura e a implantação do centro de convivência, com o intuito de promover a integração social dos alunos.

$\mathrm{O}$ acesso ao ensino superior, além dessas questões, passa pela qualidade da escola básica. Os exames vestibulares da UFGD realizados com o apoio do Lapei (Programa Incluir) asseguraram a língua portuguesa como segunda língua e a presença do intérprete. Sete candidatos surdos participaram das provas, em janeiro de 2009, sem, contudo, obterem aprovação nas provas objetivas.

A preocupação com a transformação da cultura universitária tem sido constante na UFGD. Além das ações do Lapei, foi implementada a disciplina de Libras em todos os cursos de licenciatura e instituíram-se na grade curricular do Programa de Mestrado em Educação duas disciplinas: uma destinada à discussão sobre políticas públicas de inclusão e outra sobre educação especial, ambas voltadas para a formação do professor pesquisador numa perspectiva de educação inclusiva.

\section{Considerações finais}

As políticas públicas de inclusão no ensino superior, no Estado de Mato Grosso do Sul, deparam-se com o enfrentamento de problemas relativos à promoção de condições mais equitativas de oportunidades e de acesso aos exames vestibulares.

Apesar dos avanços, das políticas afirmativas e das inovações, as ações para a inclusão nesse nível de ensino ainda são frágeis, em virtude da ausência de normas nos planos de desenvolvimento institucional e nos projetos político-pedagógicos das universidades estudadas.

Observa-se a ausência de políticas e de ações contínuas capazes de diminuírem as tensões entre as condições de acesso oferecidas frente à diferença e à diversidade linguística, cultural e de formação, apresentadas pelos candidatos oriundos das escolas públicas. Nesse sentido, a UFGD têm se esforçado para cumprir com as metas de ampliação do acesso, da permanência e da inclusão dos acadêmicos nos diferentes cursos. 
Outrossim, cabe assinalar a necessidade de investimentos contínuos para essas ações, uma vez que o Incluir é um Programa elaborado por editais, que depende do interesse, da boa vontade e das prioridades traçadas pela instituição promotora da acessibilidade; no entanto, se não houver um compromisso do coletivo universitário com rupturas paradigmáticas, nos aspectos relacionais e inovações nas práticas pedagógicas e no processo de avaliação, o acesso e a permanência dos alunos com surdez ficam prejudicados.

As pesquisas indicam que o direito linguístico tem sido garantido em parte; a presença do intérprete não determina sucesso e promoção da aprendizagem. Poucas universidades brasileiras, como também as do Estado de Mato Grosso do Sul, não realizam as provas e os exames vestibulares em Libras.

Os resultados das pesquisas mostram que a presença do intérprete, na sala de aula, não tem sido suficiente para ampliar o acesso e a permanência no ensino superior. A hipótese que levanto é que há ausência de articulação entre a política de educação especial e o ensino superior, o que se evidencia na falta de formação de professores para atuarem nesse nível de ensino, tanto como participantes das bancas avaliadoras do vestibular, quanto como profissionais para o apoio e o suporte ao processo de inclusão instrucional no interior das diferentes faculdades.

Outra questão que emerge é a necessidade de que as pessoas surdas possam concorrer a diferentes carreiras universitárias, tendo considerada sua produção linguística peculiar à cultura surda. Essas ações significam pensar o outro não pela negação, nem pela afirmação exacerbada da diferença. Reconhecer a cultura surda e o direito linguístico como política pública passa também por contemplar a avaliação do vestibular dentro da concepção de educação bilíngue: Libras como primeira língua de instrução da pessoa surda e língua portuguesa como segunda língua na modalidade escrita.

Finalmente, recorro mais uma vez ao pensamento de Deleuze, para pensar a emergência de transformações das práticas pedagógicas no ensino superior: "Queremos pensar a diferença em si mesma e a relação do diferente com o diferente, independentemente das formas de representação que as conduzem ao mesmo e as fazem passar pelo negativo" (Deleuze, 2006, p. 16).

Embora a expansão das oportunidades para as pessoas surdas no ensino superior ocorra no âmbito de projetos especiais como o Letras Libras, esses cursos não deixam de ser fronteiras para a construção de uma política linguística fundada na cultura e na identidade surda e transformam-se, de certo modo, em espaço de (des)construção de discursos, rupturas e resistências.

\section{Referências bibliográficas}

APPLE, Michael W.; BURAS Kristen L. Currículo, poder e lutas: com a palavra, os subalternos. Tradução de Ronaldo Catalado Costa. Porto Alegre: Artmed, 2008. 
BRASIL. Ministério da Educação. Aviso Circular n 277/MEC/GM, de 8 de maio de 1996. Dirigido aos Reitores das IES, solicitando a execução adequada de uma política educacional dirigida aos portadores de necessidades especiais. Brasília, DF, 1996.

. Decreto $n^{\circ} 3.298$, de 20 de dezembro de 1999. In: BRASIL. Ministério da Educação. SEESP. In: GRIBOSKI, Cláudia Maffini et al. (Org.). Direito à Educação: subsídios para a gestão dos sistemas educacionais: orientações gerais e marcos legais. MEC: Brasília-DF, 2004.

Ministério da Educação. Secretaria de Educação Especial.

Decreto n 5.296, de 2 de dezembro de 2004. Brasília-DF, 2004.

Secretaria de Educação Especial. Lei no 10.436 , de 24 de abril de 2002. Dispõe sobre a Língua Brasileira de Sinais-Libras e dá outras providências. Brasília, 2002, p. 241

INEP. Censo Universitário, 2007. Disponível em: <www.inep. gov.br> Acesso em: 11 nov. 2008.

Ministério da Educação. Plano de Desenvolvimento da Educação: razões, princípios e programas. Brasília: MEC, 2007.

Ministério da Educação. Portaria n 3.284 , de 7 de novembro de 2003. Dispõe sobre requisitos de acessibilidade de pessoas portadoras de deficiências, para instruir os processos de autorização e de reconhecimento de cursos e de credenciamento de instituições. Diário Oficial da União, Brasília- DF, 2003.

Ministério da Educação. Secretaria de Educação Especial. Política Nacional de Educação Especial na perspectiva da educação inclusiva. Revista de Educação Especial, Brasília-DF: MEC-SEESP, v. 4, n. 1, jan./jun. 2008.

Ministério da Educação. Portaria no 319, de 26 de fevereiro de 1999. In: GRIBOSKI, Cláudia Maffini et al. (Org.). Direito à educação: subsídios para a gestão dos sistemas educacionais - Orientações gerais e marcos legais. MEC: Brasília-DF, 2004.

Lei no 9.394, de 20 de dezembro de 1996. Lei de Diretrizes e Bases para a Educação Nacional. Diário Oficial da União, Brasília-DF, v. 143, n. 248, 23 dez. 1996.

Senado Federal. Constituição da República Federativa do Brasil. Promulgada em 5 de outubro de 1988. Brasília-DF: Senado Federal, 1988. 
COELHO, L.L; BRUNO, M. M. G. Políticas públicas para o acesso e a permanência das pessoas surdas no Ensino Superior na cidade de Dourados-MS. In: Anais do X Encontro de Pesquisa em Educação da Anped Centro-Oeste: desafios da produção e divulgação do conhecimento, Universidade Federal de Uberlândia (UFU), 2010.

CASTANHO, Denise Molon. Política para inclusão de alunos com necessidades educacionais especiais: um estudo em universidades e centros universitário de Santa Maria-RS. Santa Maria, 2007. Dissertação (Mestrado em Educação) - Programa de Pós-graduação em Educação, Universidade Federal de Santa Maria (UFSM), Santa Maria-RS, 2007.

DELEUZE, Gilles. Diferença e repetição. Tradução de Luís Orlandi e Roberto Machado. 2. ed. Rio de Janeiro: Graal, 2006.

DERRIDA, Jacques. A diferença. Margens da Filosofia. Tradução de Joaquim Torres Costa e Antônio M. Magalhães. Porto, Portugal: RÉS, 1976.

FORSTER, Mari Margarete dos Santos; FAGUNDES, Maurício César Vitória. Inovações educativas na sala de aula universitária. In: SILVA JUNIOR, João dos Reis et al. (Org.). Reforma Universitária: dimensões e perspectivas. Campinas-SP: Alínea, 2006.

FOUCAULT, Michel. Nietzsche, Freud e Marx. Porto: Biblioteca Nova Crítica, 1980.

GESSER, A. Libras? Que Língua é essa? Crenças e preconceitos em torno da língua de sinais e da realidade surda. São Paulo: Parábola Editorial, 2009.

MOREIRA, Laura Ceretta. Universidades e alunos com necessidades educacionais especiais: das ações institucionais às práticas pedagógicas. São Paulo, 2004. Tese (Doutorado em Educação) Universidade de São Paulo (USP), 2004.

PERLIN, G. Identidade surda e currículo. In: LACERDA, C.B; GOES, M.C.R. (Orgs.). Surdez: processos educativos e subjetividade. São Paulo: Lovise, 2000.

QUADROS, R. M; STUMPF, M.R. Estudos Surdos IV: Série Pesquisas. Rio de Janeiro: Petrópolis: Arara Azul, 2009.

SANDER, R. Questões de intérprete de língua de sinais na universidade. In: LODI, A.C.B et AL. Letramento e minorias. Porto Alegre: Mediação, 2009. 
SKLIAR, SKLIAR, Carlos (Org.). Educação e exclusão: Abordagens sócio-antropológicas em educação especial. Porto Alegre: Mediação, 1997.

STROBEL,K. As Imagens do outro sobre a cultura surda. Florianópolis: Editora UFSC, 2008.

TORRES, Elisabeth Fátima. As perspectivas de acesso ao ensino superior de jovens e adultos da educação especial. Florianópolis, 2002. 196 f. Tese (Doutorado em Engenharia de Produção) - Programa de Pós-Graduação em Engenharia de Produção, Universidade de Santa Catarina (UFSC), 2002.

VALDÉS, Maria Teresa Moreno (Org.). Inclusão de pessoas com deficiência no ensino superior no Brasil: caminhos e desafios. Fortaleza: Eduece, 2006, 174 p.

WORLD CONFERENCE ON EDUCATION FOR ALL (WCEFA). Declaração mundial sobre educação para todos e plano de ação para satisfazer as necessidades básicas de aprendizagem. Jomtien, Tailândia: Unesco, 1990. Disponível em: < http://www.acaoeducativa.org.br/downloads/ Declaracao_Jomtien.pdf $>$.

WORLD CONFERENCE ON EDUCATION FOR ALL (WCEFA). Declaração de Salamanca e linha de ação sobre as necessidades educativas especiais. Brasília-Unesco, 1994.

Marilda Moraes Garcia Bruno, doutora em Educação Brasileira pela Universidade Estadual Paulista Júlio de Mesquita Filho (Unesp), campus de Marília, é professora da Faculdade de Educação e do Programa de PósGraduação em Educação da Universidade Federal da Grande Dourados (UFGD).

marildabruno@ufgd.edu.br

Recebido em 18 de abril de 2011.

Aprovado em 14 de setembro de 2011. 